\title{
Asociación entre Seropositividad al Virus de la Diarrea Viral Bovi- na, Leptospira interrogans y Neospora caninum, y la Ocurrencia de Abortos en Fincas de Pequeños Productores del Cordón Lechero de Boyacá, Colombia
}

\author{
Association between Seropositivity to BVD Virus, Leptospira interrogans AND \\ Neospora caninum and Abortions in Small Holder Farms in the Dairy Belt of \\ Boyacá, Colombia
}

\author{
Giovanni Moreno Figueredo ${ }^{1.5}$, Efraín Benavides Ortiz ${ }^{2}$, Bernardo Guerrero ${ }^{3}$, \\ Anastasia Cruz Carrillo ${ }^{4}$
}

\section{Resumen}

\begin{abstract}
El objetivo del estudio fue determinar mediante un estudio de casos y controles, la asociación entre seropositividad a algunos agentes infecciosos y el reporte de alteraciones reproductivas en animales y fincas de la región de Boyacá, Colombia. Se consideró como «caso» a fincas $(\mathrm{n}=5)$ con una frecuencia de ocurrencia de abortos superior al $10 \%$ y como «control» $(\mathrm{n}=10)$ a fincas con frecuencias de aborto menor de $3 \%$. En cada finca, se recolectaron muestras de sangre de 10 novillas, 10 vacas de $1^{\text {er }}$ y $2^{\text {do }}$ parto y 10 vacas de $>2$ partos. Se utilizó la prueba de seroneutralización para la detección de anticuerpos contra el virus de la diarrea viral bovina (DVB), la prueba de microaglutinación para siete serovares de Leptospira interrogans y la prueba de inmunofluorescencia indirecta para Neospora caninum. Las mayores seropositividades fueron para DVB $(76.4 \%, 15 / 15$ fincas), serovar Hardjo (23.1\%, 14/15 fincas) y N. caninum (10.7\%, 12/15 fincas), sin diferencias significativas entre fincas casos y fincas control. Se comparó el resultado serológico de cada animal como factor de riesgo frente a la condición de aborto encontrando un Odds Ratio (OR) de 10.11 para DVD y 3.88 para Hardjo. No se encontró asociación como factor de riesgo de abortos para los demás patógenos.
\end{abstract}

Palabras clave: aborto; ganado bovino; enfermedades infecciosas; enfermedades de la reproducción; factores de riesgo

${ }^{1}$ Grupo de Investigación IRABI, Programa de Medicina Veterinaria, Fundación Universitaria Juan de Castellanos, Tunja, Colombia

${ }^{2}$ Centro de Investigación en Medicina y Reproducción Animal-CIMRA, Programa de Medicina Veterinaria, Facultad de Ciencias Agropecuarias, Universidad de La Salle, Bogotá, Colombia

${ }^{3}$ Laboratorios Calier Andes, Bogotá, Colombia

${ }^{4}$ Grupo de Investigación GIBNA, Programa de Medicina Veterinaria y Zootecnia, Universidad Pedagógica y Tecnológica de Colombia, Bogotá, Colombia

${ }^{5}$ E-mail: gmorenof@jdc.edu.co

Recibido: 9 de diciembre de 2016

Aceptado para publicación: 19 de junio de 2017 
The aim of this study was to determine, through a case-control study, the association between sero-positivity to some infectious agents and the report of reproductive alterations in animals and farms in Boyacá, Colombia. «Case» farms $(\mathrm{n}=5)$ were considered those with a frequency of abortions higher than $10 \%$ and as «control» farms $(n=10)$ those with abortion frequencies lower than $3 \%$. In each farm, blood samples were collected from 10 heifers, 10 cows from $1^{\text {st }}$ and $2^{\text {nd }}$ calving and 10 cows from $>2$ calvings. It was used the seroneutralization test for the detection of antibodies against bovine viral diarrhea virus (DVB), the microagglutination test for seven serovars of Leptospira interrogans and the indirect immunofluorescence test for Neospora caninum. The highest seropositivity were for DVB ( $76.4 \%, 15 / 15$ farms), serovar Hardjo (23.1\%, 14/15 farms) and $N$. caninum $(10.7 \%, 12 / 15$ farms) and without significant differences between case farms and control farms. The serological result of each animal as a risk factor against the abortion condition was evaluated, finding an Odds Ratio (OR) of 10.11 for DVD and 3.88 for Hardjo. No association was found as a risk factor for abortions for other pathogens.

Key words: abortion; cattle; infectious diseases; reproductive diseases; risk factors

\section{INTRODUCCIÓN}

En la medicina y reproducción bovina, se entiende como enfermedad reproductiva, aquella enfermedad que imposibilita o dificulta la fecundación, el mantenimiento de una gestación completa o la obtención de una cría con posibilidades de vida, o bien, aquella enfermedad que afecta los parámetros reproductivos propios del sistema de producción que se maneje (Anderson, 2007). En consecuencia, al producirse infertilidad, se observa aumento de los días abiertos y del intervalo entre partos, además de poder observar muertes embrionarias, abortos, malformaciones fetales y nacimiento de terneros débiles. De manera paralela, algunas de ellas conducen a cuadros clínicos que involucran órganos o sistemas distintos al reproductivo, capaces de afectar a machos y hembras de cualquier edad, conduciendo en algunos casos a la muerte. Estas alteraciones no solamente afectan la salud del hato, sino que ejercen influencia directa, sobre la producción, teniendo en algunos casos importancia zoonótica (Anderson 2007).
Las metas del plan estratégico de la ganadería colombiana (Fedegan, 2006) indican que las bajas tasas de natalidad continúan siendo una de las principales limitaciones para el desarrollo de la industria ganadera; sin embargo, se desconocen componentes epidemiológicos de los agentes causantes de las principales enfermedades de la reproducción bovina, siendo la mayoría de las investigaciones sobre el tema dirigidas al reporte de los agentes causales (Vera et al., 2006; Vera y Betancur, 2008) o de estudios epidemiológicos transversales de prevalencia (Griffiths et al., 1982; Morrison et al., 1991; Betancur et al., 2007), los cuales no permiten determinar relaciones causa - efecto (Otte et al., 1995; Thrusfield, 2007).

El diagnóstico preciso de las causas de aborto y de alteraciones reproductivas de los bovinos es complejo y requiere de la cooperación entre el veterinario de campo y el laboratorio de diagnóstico veterinario (Anderson, 2007), lo cual debe ser tamizado a través de la evidencia epidemiológica (Otte et al., 1995; Gröhn y Rajala-Schultz, 2000). Las causas infecciosas asociadas al aborto 
bovino incluyen agentes bacterianos (leptospirosis y brucelosis, principalmente), virales (diarrea viral bovina [DVB]), micóticos y protozoos (Neospora caninum) (Anderson, 2007).

El objetivo de esta investigación fue determinar, mediante un estudio epidemiológico retrospectivo de casos y controles (Otte et al., 1995; Thrusfield, 2007), la asociación entre seropositividad a algunos agentes infecciosos y el reporte de alteraciones reproductivas en animales y fincas de pequeños productores de Boyacá, Colombia.

\section{Materiales y Métodos}

El estudio se realizó en el cordón lechero de Boyacá, el cual abarca las provincias de Centro, Sugamuxi y Tundama del departamento de Boyacá, Colombia, y entre otros, los municipios de Ventaquemada, Oicatá, Tuta, Tunja, Duitama, Sotaquirá, Paipa, Soracá e Iguaque (Ortiz et al., 2005; Dehaquiz et al., 2012).

Se realizó un estudio epidemiológico de casos y controles (Thrusfield, 2007), donde las fincas participantes fueron seleccionadas por conveniencia con base en su voluntad de cooperación, el cumplimiento de requerimientos metodológicos y de aporte de información del estudio. Las fincas incluidas en el estudio correspondieron a medianos productores con 15-30 animales y 20-30 ha destinadas a ganadería. Son fincas de mediana tecnificación en las que se practica inseminación artificial y donde algunas tienen ordeño mecánico. La Figura 1 muestra los municipios del cordón lechero de Boyacá que incluyeron fincas de pequeños ganaderos que participaron en el estudio.

Se consideraron como «caso» aquellas fincas con una frecuencia de ocurrencia de abortos superior al 10\% (5 fincas) y se catalogó como fincas «controles» (10 unidades de producción) aquellas que reportaban la ocurrencia de ese evento con una frecuencia inferior al 3\% (Otte et al., 1995). En cada finca se recolectó información complementaria sobre inventario ganadero, eventos de salud y producción (nacimientos, enfermedad, abortos, etc.), y se evaluó la condición reproductiva de los animales mediante palpación rectal de los órganos reproductivos y el historial reproductivo de la finca.

Se recolectaron muestras de sangre de 10 novillas, de 10 vacas entre el primer y segundo parto y de 10 vacas de tres o más partos en cada finca participante (Hathaway et al., 1986). Las muestras fueron centrifugadas y el suero resultante fue almacenado a $-70{ }^{\circ} \mathrm{C}$ y enviado a la Universidad de Parma, Italia, donde se realizaron las pruebas serológicas. El laboratorio de esta universidad es considerado laboratorio de referencia para la Unión Europea para los agentes patógenos en estudio.

Las muestras fueron analizadas para determinar la presencia de anticuerpos contra el virus de la diarrea viral bovina (DVD), Leptospira interrogans y Neospora caninum. Para el virus de DVB se utilizó la prueba de seroneutralización (SN), donde se prepararon diluciones de cada suero problema desde 1:2 hasta 1:256, según Reinhard et al. (2001). Los títulos serológicos se convirtieron a una escala continua en logaritmo en base 2 del recíproco de la dilución utilizada, considerando un suero positivo aquel que presente títulos mayores o iguales a ocho y como suero negativo aquel con títulos menores a cuatro.

Para el diagnóstico de serovares de $L$. interrogans se utilizó la prueba de microaglutinación lisis, donde cada suero problema fue procesado por duplicado y en diluciones 1:25, 1:50 y 1:100. Se trabajó con los serovares $L$. interrogans, $L$. hardjobovis, $L$. pomona, L. bratislava, L. gryppothyphosa, L. canicola y L. tarassovi (OMS, 1987). Los serovares seleccionados fueron los de mayor reporte en el país y que, además, correspon- 


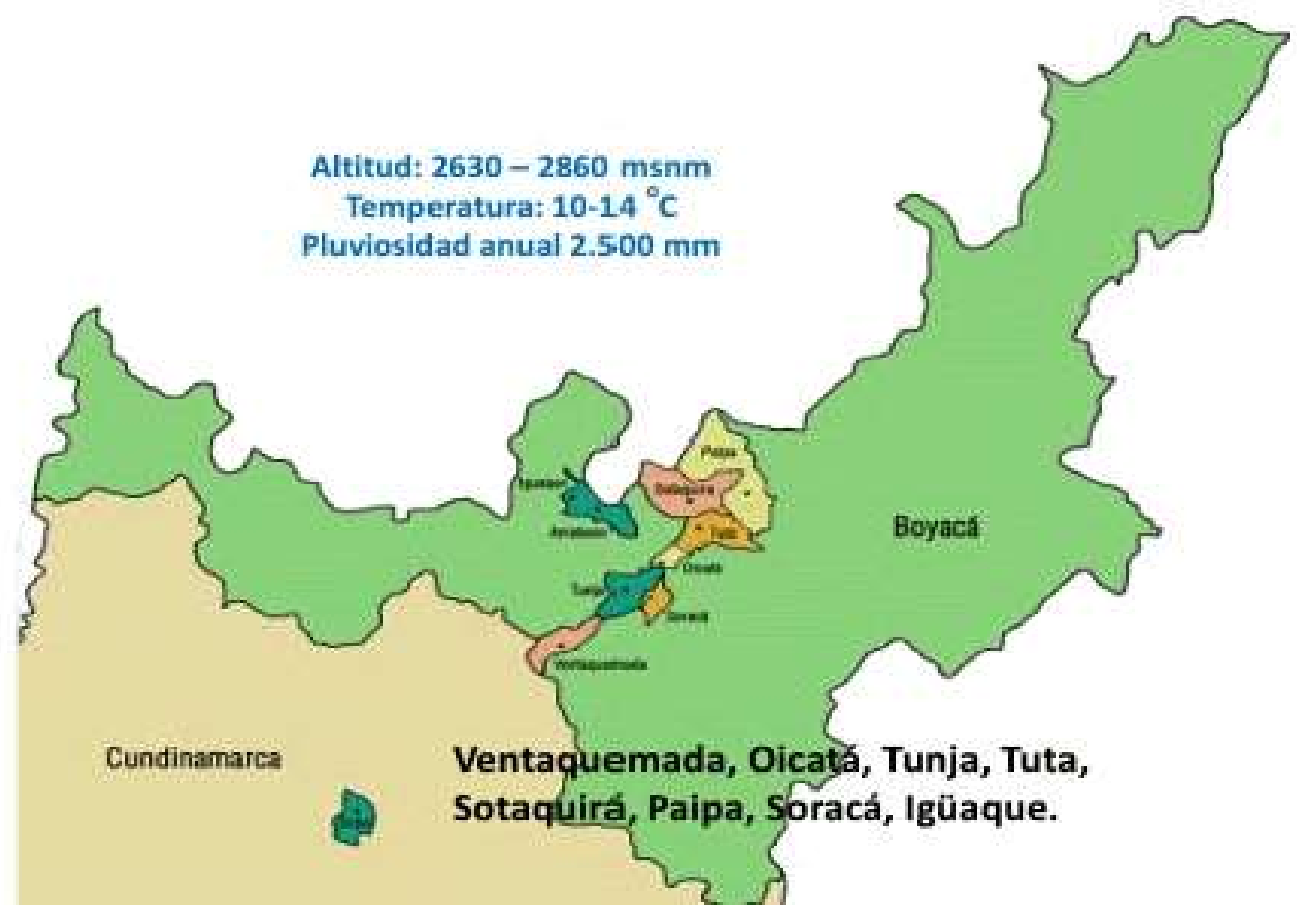

Figura 1. Municipios del cordón lechero de Boyacá con fincas participantes del estudio

den a los serovares incluidos en las vacunas utilizadas contra este patógeno.

El diagnóstico de Neospora caninum se realizó mediante una prueba de inmunofluorescencia indirecta (IFI) utilizando como antígeno a taquizoitos del parásito (Conrad et al., 1993).

El análisis estadístico incluyó la preparación de tablas de contingencia comparando positivos y negativos a cada agente etiológico en las fincas casos y fincas controles, así como la comparación de proporciones mediante Chi cuadrado, considerando un nivel de confianza del 95\%. Los factores de riesgo, principalmente la razón de probabilidades (Odds Ratio, OR) se estimaron con la ayuda del programa WinEpi (de Blas et al., 2000). Un segundo análisis comparó el riesgo de ocurrencia de aborto en animales positivos y negativos a cada prueba serológica.

\section{Resultados y Discusión}

Se recolectaron muestras de 450 animales de 15 fincas (5 casos, 10 controles). De estos, 58 animales habían presentado el evento de aborto. La seropositividad para DVB fue de $76.4 \%$ para el total de animales evaluados, para el serovar hardjo fue $23.1 \%$ en 14 fincas y para $N$. caninum fue $10.7 \%$ en 12 de las 15 fincas, pero sin que hubiera diferencias significativas en las frecuencias de positividad para cada agente etiológico entre fincas caso y fincas control.

La frecuencia de positividad para el virus de DVB en las fincas caso fluctuó entre 53.3 y $100 \%$ (promedio $76.0 \%$ ), mientras en las fincas control varió entre 30 y $100 \%$ (promedio 76.7\%) (Cuadro 1), sin diferencias entre fincas caso y fincas control $(X 2=0.014$; $\mathrm{p}=0.906$ ). 
Cuadro 1. Comparación de la frecuencia de positividad serológica al virus de la diarrea viral bovina (DVD) en las fincas caso y fincas control en el cordón lechero de Boyacá (30 muestras por finca)

\begin{tabular}{clcc}
\hline \multirow{2}{*}{ Finca } & \multirow{2}{*}{ Grupo } & \multicolumn{2}{c}{ Positivos } \\
\cline { 3 - 4 } & & $\mathrm{n}$ & $\%$ \\
\hline 1 & Caso & 30 & 100.0 \\
2 & Caso & 27 & $90-0$ \\
3 & Caso & 16 & 53.3 \\
4 & Caso & 18 & 60.0 \\
5 & Caso & 23 & 76.7 \\
6 & Control & 23 & 76.7 \\
7 & Control & 9 & 30.0 \\
8 & Control & 28 & 93.3 \\
9 & Control & 24 & 80.0 \\
10 & Control & 27 & 90.0 \\
11 & Control & 17 & 56.7 \\
12 & Control & 30 & 100.0 \\
13 & Control & 23 & 76.7 \\
14 & Control & 22 & 73.3 \\
15 & Control & 27 & 90.0 \\
\hline Total & & 344 & 76.4 \\
\hline
\end{tabular}

La mayor frecuencia de seropositividad se observó para el vDVB, seguido por $L$. hardjo y N. caninum (Cuadro 2). Para el caso de $L$. hardjo, la seropositividad en las fincas caso fue de $25.3 \%(0-50 \%)$ y en las fincas control de $22.0 \%$ (3.3-46.6\%), sin diferencias significativas entre el tipo de finca. Las frecuencias de positividad para los otros serovares fueron bajas, mientras que fue nula para L. tarassovi (Cuadro 2).

El promedio de seropositividad para $N$. caninum fue de $10.7 \%$, tanto para las fincas caso como para las fincas control. En las primeras, los promedios de seropositividad por finca fluctuaron entre 0 y $20 \%$ y en las fincas control entre 0 y $23.3 \%$.

Ninguna de las fincas participantes declaró utilizar vacunas para el complejo reproductivo bovino (IBR, DVB, Leptospira), lo que coincide con observaciones previas de fincas de la región, donde solo se emplean vacunas contra fiebre aftosa y brucelosis, conducta asociada con las campañas oficiales (Ortiz et al., 2005). Esto indica que los anticuerpos hallados en los animales se debieron a infecciones de campo.

Reportes previos en Colombia sobre la prevalencia de reactores serológicos al virus de DVB indican 47.2\% (Griffiths et al., 1982), y aun menores, como el $6.4 \%$ en el $49 \%$ de las fincas en la región Caribe (Morrison et al., 1991), y más recientemente, de $29.4 \%$ en el municipio de Montería (Betancur et al., 2007). Por otro lado, en el trópico alto colombiano, se destaca el reporte de $83 \%$ de toros reactores en la Sabana de Bogotá (Góngora et al., 1995). Esto parece indicar que este virus se transmite más fácilmente entre animales en las condiciones de trópico alto; sin embargo, las fincas con problemas de abortos (fincas caso) presentaron niveles de seropositividad similares al de las fincas con baja ocurrencia de aborto (fincas control), de allí que la prueba de asociación no permitió inferir que este agente etiológico fuera un factor de riesgo en el modelo basado en la clasificación de la finca.

Con relación a Leptospira, los resultados coinciden con lo que se afirma respecto a que el serovar Hardjo es el de más frecuente transmisión en el trópico colombiano (Otte, 1992). El estudio de Griffiths et al. (1982), llevado a cabo en Colombia hace 35 años indicó una prevalencia de $21.7 \%$ en todas las regiones y de $14.4 \%$ en la región andina (Griffiths et al., 1982); luego en el estudio en fincas de Córdoba y Sucre (Morrison et al., 1991) se presenta una evidencia de contacto con el patógeno en el $100 \%$ de las fincas y en $41.8 \%$ de los animales. Un estudio longitudinal prospectivo de dos años de seguimiento demostró la complejidad de las dinámicas de transmisión de Hardjo en los ecosistemas del trópico bajo y donde se demostró asociación entre el evento seropositividad a este patógeno y alteraciones reproductivas (Otte, 1992). Un segundo estudio llevado a cabo en el piedemonte Llanero demostró la bondad del uso de un abordaje de estudio de casos y controles, don- 
Cuadro 2. Porcentaje de reactores serológicos a diversos agentes infecciosos en las fincas caso y las fincas control en el cordón lechero de Boyacá (30 muestras por finca)

\begin{tabular}{lcccc}
\hline Agente patógeno & Fincas caso & $\begin{array}{c}\text { Fincas } \\
\text { control }\end{array}$ & $\mathrm{X}^{2}$ & $\mathrm{p}$ \\
\hline DVD & 76.0 & 76.7 & 0.027 & 0.869 \\
Leptospira & & & & \\
$\quad$ Hardjo & 25.3 & 22.0 & 0.613 & 0.464 \\
Pomona & 3.3 & 2.0 & n.v. & \\
Bratislava & 1.3 & 0.3 & n.v. & \\
Gryppothyphosa & 3.3 & 0 & n.v. & \\
$\quad$ Canicola & 4.7 & 2.7 & 1.230 & 0.267 \\
Neospora caninum & 10.7 & 10.7 & n.a. & \\
\hline
\end{tabular}

n.v. Cálculo de Chi cuadrado no válido por alto porcentaje de celdas con valor esperado inferior a cinco n.a. La prueba no aplica cuando ambos porcentajes son idénticos

Cuadro 3. Frecuencia de seropositividad a diversos agentes infecciosos en animales que han abortado y animales sin historia de aborto, y factores de riesgo en el cordón lechero de Boyacá.

\begin{tabular}{lcccc}
\hline Agente patógeno & $\begin{array}{c}\text { Positivos con } \\
\text { aborto }\end{array}$ & $\begin{array}{c}\text { Positivos sin } \\
\text { aborto }\end{array}$ & OR & LC95\% \\
\hline DVD & 96.6 & 73.5 & 10.11 & $2.4-42.2$ \\
Leptospira & & & & \\
$\quad$ Hardjo & 48.3 & 19.4 & 3.88 & $2.2-6.9$ \\
$\quad$ Pomona & 5.2 & 2.0 & 2.65 & $0.7-10.2$ \\
$\quad$ Canicola & 6.9 & 2.8 & 2.57 & $0.8-8.3$ \\
Neospora caninum & 10.3 & 10.7 & 0.96 & $0.4-2.4$ \\
\hline
\end{tabular}

de se encontró una frecuencia significativamente mayor de reactores positivos en fincas que habían experimentado altas tasas de abortos y nacimiento de terneros débiles (Otte et al., 1995).

$N$. caninum es de reciente descripción en estudios nacionales. Una evaluación serológica basada en una prueba de ELISA comercial dio como resultado $54 \%$ de positividad (Zambrano et al., 2001) y en otro estudio en el trópico bajo (Córdoba) en vacas con problemas reproductivos se encontró una seropositividad de 10.2\% (Oviedo et al.,2007). Ese resultado es muy similar al encontrado en esta investigación, en la que, además, no hubo evidencia epidemiológica de que esta coccidia esté implicada como causa de aborto en fincas con tasas de aborto superiores al $10 \%$. 
Debido a que no se pudo demostrar asociación causal entre abortos y los agentes etiológicos estudiados, basado en un modelo de discriminación de fincas casos y fincas control, se analizaron los resultados considerando como factor de riesgo el ser positivo serológicamente a un agente mientras que la enfermedad a considerar fue la ocurrencia de abortos en los animales individuales, independientemente de la finca a la que perteneciera. Los resultados del análisis indicaron un OR de 10.1 para el virus de DVB (Límites de confianza del 95\% [LC95\%]: 2.4-42.1) y de 3.88 para Hardjo (LC95\%: 2.2-6.9); resultados que indican asociación entre las dos variables consideradas. En los otros patógenos en estudio no se encontró asociación como factor de riesgo de abortos en la región (Cuadro 3).

\section{Conclusiones}

- El virus de la diarrea viral bovina (DVD) y el serovar Hardjo de Leptospira interrogans fueron factores de riesgo para la ocurrencia de abortos en animales de la región de Boyacá, Colombia, más no así Neospora caninum y otros serovares de Leptospira.

- La categorización por fincas caso y control no permitió detectar factores de riesgo en cuanto a la categorización de fincas con problemas de aborto o fincas consideradas normales.

\section{Literatura Citada}

1. Anderson ML. 2007. Infectious causes of bovine abortion during mid- to lategestation. Theriogenology 68: 474-486. doi:10.1016/j.theriogenology. 2007. 04.001

2. Betancur CA, Gogorza LM, Martinez FG. 2007. Seroepidemiología de la diarrea viral bovina en Montería (Córdoba, Colombia). Analecta Vet 27(2): 11-16.
3. Conrad PA, Sverlow KW, Anderson $M L$, Rowe J, BonDurant R, Tuter G, Breitmeyer $R$, et al. 1993. Detection of serum antibody responses in cattle with natural or experimental Neospora infections. J Vet Diagn Invest 5: 572-578. doi: $10.1177 / 104063879300500412$

4. De Blas N, Ortega C, Frankena K, Noordhuizen J, Thrusfield M. 2000. Win Episcope 2.0. A software for quantitative veterinary epidemiology Red Ratio, Epidecon. Edinburgh, UK: University of Edinburgh.

5. Deháquiz MJE, Bermúdez CLT, Rodríguez CLF. 2012. Environmental management model for small dairies in the Industrial Corridor of Boyaca (Colombia). Agron Colomb 30: 141-148.

6. [FEDEGAN] Federación Colombiana de Ganaderos. 2006. Plan estratégico de la ganadería colombiana 2019. Bogotá: Ed Sanmartín Obregón. 273 p.

7. Góngora A, Villamil L, Vera V, Ramírez G, Parra J. 1995. Diagnóstico de las principales enfermedades reproductivas en toros de la sabana de Bogotá. Énfasis en rinotraqueitis infecciosa bovina (RIB). Rev Fac Med Vet Zootec 42(1): 37-42.

8. Griffiths IA, Villamil LC, Gallego MI. 1982. Factores de infertilidad y pérdidas económicas en ganado de leche en Colombia. Bogotá, Colombia: ICA. $154 \mathrm{p}$.

9. Gröhn YT, Rajala-Schultz PJ. 2000. Epidemiology of reproductive performance in dairy cows. Anim Reprod Sci $60-$ 61: 605-614. doi: 10.1016/S0378-4320 (00)00085-3

10. Hathaway SC, Little TW, Pritchard DG. 1986. Problems associated with the serological diagnosis of Leptospira interrogans serovar hardjo infection in bovine populations. Vet Rec 119: 84-86.

11. Morrison R, Navarrete M, Orjuela J, Otte $E$. 1991. Salud y productividad en bovinos de la Costa Norte de Colombia. Rev Mundial Zootec 68: 43-51.

12. [OMS] Organización Mundial de la Salud. 1987. Leptospirosis. Manual de métodos para el diagnóstico de laboratorio. 30: 46 
13. Ortiz R, Benavides E, Ortiz D. 2005. Estrategias de medicina veterinaria preventiva utilizadas en ganaderías del cordón lechero de Boyacá. Rev Acovez 35: 10-12.

14. Otte J. 1992. Diagnóstico epidemiológico de la leptospirosis bovina. En: Mem Simposio Internacional sobre estado actual y perspectivas del diagnóstico en salud y producción animal. Santafé de Bogotá, Colombia: ICA- GTZ.

15. Otte MJ, Ravenborg T, Hüttner K. 1995. A pilot study of elevated abortion and stillbirth ratios in cattle in the foothills of the eastern plains of Colombia. Prev Vet Med 22: 103-113. doi: 10.1016/01675877(94)00394-X

16. Oviedo ST, Betancur HC, Mestra PA, González TM, Reza GL, Calonge GK. 2007. Estudio serológico sobre neosporosis en bovinos con problemas reproductivos en Montería, Córdoba, Colombia. Rev MVZ Córdoba 12: 929-933.

17. Reinhardt G, Carrasco L, Tadich N, Riedemann S. 2001. Comparación en- tre dos técnicas de diagnóstico para diarrea viral bovina (Dvb) en 50 predios de la X Región, Chile: seroneutralización y enzimoinmunoensayo indirecto (Elisa-I). Arch Med Vet 33: 173-183. doi:/10.4067/ S0301-732X2001000200006

18. Thrusfield M. 2007. Veterinary epidemiology. $3^{\text {rd }}$ ed. Oxford, UK: Blackwell Science Ltd. $335 \mathrm{p}$.

19. Vera V, Betancur C. 2008. Aislamiento del virus herpes bovino tipo 1 en bovinos del departamento de Córdoba - Colombia. Rev MVZ Córdoba 13: 1495-1503.

20. Vera VJ, Ramírez GC, Villamil LC, Moreno de Sandino M, Jaime J. 2006. Biología molecular, epidemiología y control de la rinotraqueítis bovina infecciosa y de la diarrea viral bovina. Bogotá: Universidad Nacional de Colombia. $80 \mathrm{p}$.

21. Zambrano J, Cotrino V, Jimenez $C$, Romero M, Guerrero B. 2001. Evaluación serológica de Neospora caninum en bovinos en Colombia. Rev Acovez 26: 5-10. 